\title{
El cuerpo como herramienta del intérprete en el performance musical
}

\author{
Lic. Saraí Stelia Noriega Peralta \\ stelianorper@gmail.com \\ Dra. Diana Brenscheidt gen. Jost \\ diana.brenscheidt@unison.mx \\ Universidad de Sonora \\ Departamento de Bellas Artes
}

Resumen: Ubicándose teórica- y metodológicamente dentro de los estudios del performance, el interés de este trabajo se centra en la presencia corporal del intérprete en relación con los demás actores de un proceso musical, el cual transcurre siempre dentro de un distinto contexto social y cultural.

Partimos de un acercamiento a los estudios del performance, sus antecedentes en la lingüística, la ciencia del teatro y la antropología, para revisar en un segundo paso las repercusiones de esa corriente en la investigación musicológica actual.

Enfocándose en el mundo de la música occidental de concierto, específicamente el formato del recital, que trae consigo un catálogo de convenciones y reglas no-escritas referente al comportamiento social de todos sus actores, se investiga y analiza el trabajo corporal de la cantante Barbara Hannigan en su interpretación de la obra Mysteries of the Macabre de György Ligeti, con la London Symphony Orchestra, bajo la batuta de Sir Simon Rattle.

Con este trabajo se busca observar una nueva propuesta del performance en el formato del recital, con el objetivo de destacar la importancia del entrenamiento y de la expresión corporal en el músico académico; así como cuestionar los cánones establecidos con la intensión de plantear la necesidad de nuevos elementos discursivos para el intérprete, que vayan de acuerdo con las exigencias de la época actual.

Palabras clave: Performance, Música, Intérprete

\section{Introducción}

La investigación musicológica tradicionalmente parte del estatuto de la obra como eje central, siendo entonces el análisis de la partitura, la cual contiene los intereses e indicaciones del compositor, la herramienta principal para el intérprete. Sin embargo, la época actual nos permite ser partícipes de cambios en dicha concepción tanto en la musicología como en las prácticas tradicionales que enmarcan la cultura de la música (académica) occidental. La influencia de los Estudios del Performance en la historiografía musical, así como las disciplinas escénicas en el intérprete lírico, permiten la observación de la interpretación musical como una estructura social-cultural en la que el intérprete y la audiencia se observan en el mismo grado de importancia que el texto o la partitura.

\section{Los Estudios del Performance}

Los Estudios del Performance tienen su origen en la lingüística, la antropología y el teatro (Madrid, 2009, p. 5). En la lin- 
güística, dicho nacimiento se asocia con unas charlas que J. L. Austin impartió en la Universidad de Harvard, las cuales después se publicaron bajo el nombre de Cómo hacer cosas con palabras. Surge entonces la corriente que después se denominaría Teoría de los actos del habla, la cual fundamenta una de las bases de los Estudios del Performance. A su vez, estos dos campos de estudio enfocan su interés en las formas particulares de expresión, es decir, en la creatividad de los usos del habla, y no sólo en la enunciación como una estructura formal (Taylor, 2011, p. 16). Algunas enunciaciones contienen una acción intrínseca, por ejemplo, -sí, acepto- en un contexto legal, como una boda, un acto de protesta, etc.

Por otro lado, Victor Turner en la antropología, junto a Richard Schechner en el teatro, reconocen puntos de encuentro entre estas dos disciplinas, desde la observación de fenómenos sociales tales como el ritual. En este contexto, Schechner acuña el concepto de "conducta restaurada" el cual define como un proceso multi-escénico, que ha sido ensayado, preparado, presentado y puesto a disposición. Este autor observa los "performances", como acciones o eventos humanos construidos a través de la conducta restaurada, en otras palabras, un "performance" es cualquier comportamiento que ha sido efectuado más de una vez. En 1981, Turner y Schechner organizan la "Conferencia mundial del Ritual y Performance". A partir de este evento, los dos autores se preguntaron si este comportamiento teatral que sucede tanto en los ritos, como en las conductas restauradas o performances, fungía como un lenguaje estructurado por movimientos físicos, sonidos y otras expresiones corporales (Komitee, 2013, pp. 5-7).
Para Schechner (2012) ${ }^{1}$, los Estudios del Performance (EP de aquí en adelante) no se restringen a un campo único, así, absolutamente cualquier cosa puede ser estudiada como performance (p. 20). Alejandro Madrid (2009) explica y sitúa esta concepción en el enfoque de fenómenos tales como acciones, procesos, performances dentro de la música, danza, teatro o los rituales e, incluso, construcciones de identidades, el uso enunciativo del lenguaje, el activismo político o el uso del cuerpo en la vida cotidiana. Dichos eventos cumplen con características que se describen a través de la noción "performatividad", la cual funciona como un adjetivo o cualidad del discurso (pp. 3-4) o según Fischer-Lichte (2006), como una condición de las puestas en escena en comparación con el enfoque de un documento en los estudios de los textos dramáticos (p. 3). Así, performatividad radica en el carácter vivo del suceso y no en un documento que le da origen o en el cual esté basado.

La finalidad de los EP no es describir acciones para ser reproducidas con fidelidad, sino entender qué es lo que dichas acciones hacen en el campo cultural del cual emergen y qué les permiten hacer a la gente en su vida cotidiana (Madrid, 2009, p. 3). Siendo así, un área de estudio con limites difusos o bien, una metodología aplicable para la observación y análisis de cualquier fenómeno social.

La ambigüedad y ubicuidad del término performance es polémica hasta el momento, primeramente, por el campo abierto en el que los EP lo utilizan; y segundo, por su etimología sajona que carece de una traducción exacta al español y portugués, complicando, tanto la definición como su uso en Latinoamérica (Taylor, 2011, p. 7). Dentro de los estudios musicológicos, el

${ }^{1}$ En cambio, el término "performático" se usa para referirse al dominio tradicional del performance, a sus elementos teatrales (Madrid, 2009, p. 4). 
término ha sufrido una considerable evolución con relación al texto o partitura que se interpreta.

\section{La musicología tradicional y el giro performativo}

Dentro de los estudios musicológicos tradicionales, la obra musical es meramente concebida por el compositor, dicho pensamiento relega al intérprete (performer) de la historia de la música clásica o académica. Autores como Heinrich Schencker, Arnold Schönberg o incluso T. W. Adorno ya en la segunda mitad del siglo XX, contemplan las obras musicales como objetos artísticos, los cuales pueden prescindir del intérprete, sólo a excepción de que dicha obra sea llevada a una audiencia inhabilitada para leer la notación musical.

Está noción de "música”, guarda relación con la literatura, la cual centra su atención en el texto escrito; desde este punto de vista, una interpretación o performance musical, sucede sólo con el objetivo de comunicar la partitura a un público determinado (Cook, 2013, pp. 8-10). Lo mismo ocurrió entre el teatro y su relación directa con la literatura, de ahí el surgimiento de los Estudios Teatrales, los cuales definen la disciplina teatral a causa de su performatividad, es decir, se observa a través de la puesta en escena y no a partir de la calidad literaria de los textos (Fischer-Lichte, 2006, pp. 2-3).

Sin embargo, dentro de la musicología, alrededor de los 90's, el giro performativo se enfoca solamente en la interpretación estética e histórica de obras escritas. Es decir, según Nicholas Cook (2013) el giro performativo estudia la música como fenómeno cultural observable a través del performance, entonces concebir la música como performance, es el comienzo para que la partitura cobre sentido (pp. 1-2).
Sin embargo, el enfoque de la música en su contexto social y cultural, corresponde más a un segundo giro performativo, el cual busca entender textos musicales e interpretaciones musicales en sus propios términos, en relación con contextos culturales y sociales específicos, se pregunta "qué es la música". En cambio, desde los EP nos preguntaríamos qué es lo que la música hace y le permite hacer a la gente; en este caso, se buscaría entender "las músicas" como procesos dentro de prácticas sociales y culturales más amplias. El giro performativo en los estudios musicales se preguntaría cómo dichos procesos nos ayudan a entender la música, pero una mirada desde los EP se pregunta cómo la música nos ayuda a entender estos procesos sociales y culturales (Madrid, 2009, p. 3). De esta manera, situarnos en los EP para observar la práctica musical, facilita la investigación de puestas en escena contemporáneas, las cuales generalmente hacen uso de una variedad de recursos escénicos en conjunto con los musicales, esto en comparación con los performances tradicionales, los cuales son influenciados por la noción de "música como texto" dentro de la musicología tradicional.

\section{El recital: tradición y nuevas tendencias}

A mediados del siglo XIX, el significado del término "recital" se centra en interpretaciones de solistas o conjuntos de cámara. Durante el siglo XVIII los conciertos eran nombrados según las preferencias de los artistas, generalmente como "conciertos de beneficencia", con programas que frecuentemente consistían en selecciones de óperas y fantasías. Franz Liszt ofreció los primeros conciertos, los cuales se pueden denominar como recitales, ya que presentaba programas para solista, y se refirió a sus propios recitales diciendo "yo soy el concierto". 
Con la proliferación de alumnos y maestros de la enseñanza en el piano, el recital se volvió una institución para determinar el curso de una carrera musical. La definición de recital como un concierto para solista, fue adoptado en Francia y otros países como Inglaterra y Estados Unidos. Ya en el siglo XX, la canción se convierte en el género mayor dentro de los recitales de la época, así, los conciertos de cantantes solistas emergieron como un tipo de recital específico. El formato de recital se establece a través de obras "clásicas", es decir las más populares, las cuales se volvieron parámetro para juzgar las habilidades de los ejecutantes. Así, el recital se convierte en uno de los más comunes e importantes formatos de concierto, donde los ejecutantes se volvieron especialistas en algún área o periodo musical, esto en paralelo con el surgimiento de la música nueva (Weber, 2001, pp. 913-914).

Las enciclopedias de música nos hablan del surgimiento y la historia del recital, así como de otros formatos de concierto, desde la perspectiva del repertorio y la instrumentalización de la pieza - con lo cual se puede obtener cierta información de los intérpretes -, sin embargo, la atención en el protocolo de comportamiento tanto de intérpretes como de la audiencia, es poco abordado. Dicho protocolo o convención consta de un comportamiento, el cual engloba ciertas reglas de conducta, tanto para músicos y público, las cuales se repiten en cada concierto.

En comparación con la ópera en la cual se combina música, drama y espectáculo (H.M. Brown, 2001, p. 416), el recital prescinde de dichos elementos escénicos para efectuarse, enfocándose más específicamente en la obra musical. Sin embargo, los recitales no dejan de ser "performances", así, las reglas de comportamiento establecidas como tradición dentro de este formato de concierto, se pueden leer a través de la conducta restaurada, la cual según Schechner (2012), consiste en acciones marcadas por convenciones estéticas, ya sea acciones redificadas como "reglas del juego", "etiqueta" o "protocolo" diplomático (p. 69). En este sentido, la ubicación en el escenario y la vestimenta de los músicos tanto de la orquesta, del director y del (la) cantante, la marcada separación entre la presentación de los ejecutantes, la interpretación de la o las piezas y los agradecimientos; así como los aplausos del público después de cada sección musical o hasta el final del concierto, son las características de una conducta que se repite sin cuestionar. Se puede decir, haciendo referencia a Schechner (2011), que estas acciones no tienen un autor específico, sino que pertenecen al colectivo anónimo o son atribuidas a la tradición, puesto que la fuente de dicha conducta puede perderse, ignorarse o contradecirse, incluso la forma en que se creó y desarrolló la secuencia de la conducta, se puede ocultar, elaborar o distorsionar por el mito y la misma tradición (pp. 35, 68-69). El autor que comentamos, también observa que tanto las artes escénicas como otras áreas de divertimento, hacen uso de procedimientos del ritual. Basándose en la noción de ritual de Émile Durkheim, señala que son los performances los que escenifican patrones conocidos, tanto de comportamiento como de textos, los cuales pueden expresar ideas con el objetivo de encarnarlas.

Así, los rituales (seculares, en el caso del recital) son estructurados bajo una conducta restaurada, teniendo un aspecto de seriedad y autoridad. Sin embargo, existe un comportamiento lúdico ante la rigidez 
del ritual, denominado "juego", este es más suelto, permisivo, flexible, se mueve en distintas direcciones simultáneamente (pp, 424, 426-427; citado en Schechner 2012, pp. 102-103). Ante lo cual, el término "performance" también se puede definir como una conducta ritualizada, condicionada o infiltrada por el juego (Schechner, pp. 112, 150). Según Victor Turner (1974), este carácter lúdico es un recurso ético para las "sociedades cíclicas o repetitivas" propiciado por ideas innovadoras y cambios técnicos (p. 66).

Tanto Schechner como Turner establecieron una relación entre teatro y ritual, los cuales se concebían como formas similares de expresión de un comportamiento social. Así, a través de performances como danzas, funerales, teatro, recitales, etc., con una estructura claramente definida, es decir, un periodo de tiempo limitado, un programa organizado de actividades con un grupo de intérpretes y público en un lugar determinado; una cultura expone y presenta la imagen y el entendimiento de sí misma, a lo que Milton Singer (1959) llama cultural performance, vistos como unidades concretas observables de una estructura cultural (Singer, p. XII, citado en Fischer-Lichte, 2006 p. 10). Se infiere entonces, que el protocolo del formato de recital al cual nos referimos, es un comportamiento social-cultural, y este, a su vez, enmarca a un grupo social-cultural determinado: intérpretes y audiencia de la música académica occidental, el cual se comunica mediante la convención del recital. Sin embargo, dentro de muchos performances musicales actuales, dicho comportamiento social se modifica en ciertos aspectos, es decir, rompe con la tradición del protocolo. En estos performances, el intérprete juega un papel destacado y menos sobrio en comparación con la convención tradicional. Se podría inferir que el repertorio contemporáneo, aunado a una audiencia más receptiva a los estímulos visuales e incluso cantantes entrenados en distintas disciplinas escénicas, permite dicho rompimiento y apertura ante un comportamiento parcialmente distinto. Desde los conceptos ritual y juego, podemos observar el recital tradicional y las nuevas tendencias que rompen con algunos aspectos de esta tradición, respectivamente.

\section{El cuerpo del intérprete}

La convergencia de varias disciplinas escénicas y del arte visual para las puestas en escena de una obra musical académica, se mezclan con ideas vanguardistas, las cuales se observan más frecuentemente en las producciones operísticas, sin embargo, también están presentes en el formato de recital. Mysteries of the Macabre (1991) de György Ligeti, presentado por Barbara Hannigan junto a la Orquesta Sinfónica de Londres bajo la dirección de Sir Simon Rattle (2015), es un ejemplo palpable de las nuevas tendencias performativas en el contexto cultural del concierto.

Dichas tendencias, las cuales cada vez más se van conformando como un estilo performativo, corresponden al rompimiento parcial del comportamiento social-cultural del recital, a través de la expresión corporal del intérprete, más allá de la técnica e interpretación musical. Brenscheidt (2015), habla de "la música como acción", refiriéndose a la relación entre compositor, intérprete y público, argumentando que, en dicho conjunto, el intérprete se encuentra en medio de la relación, y este debe dar atención tanto a las intenciones musicales del compositor, como a las sensibilidades del público.

En comparación con la "música como objeto" lo cual se refiere a la noción de música desde la musicología tradicional (pp. 11-12) En este sentido, el intérprete 
hace presencia, no solo para comunicar una obra musical ante una audiencia, sino también para compartir una ideología cultural que se puede percibir a través de sus actos performativos. Dichas acciones en el escenario, establecidas en la tradición social-cultural del recital, pertenecen a un código, el cual según Fisher-Lichte (1999), se desarrolla dentro de un sistema cultural el cual contiene significados entendidos a través de las reglas del juego (código); estos significados son divergentes cuando una cultura distinta utiliza diferentes códigos para un mismo significado (pp. 18-19).

En Mysteries of the Macabre (2015) el código tradicional se modifica a través de las prácticas corporales (embodied practices) de la cantante, es decir, propone un vestuario distinto, el manejo de un personaje de principio a fin (antes y después de la interpretación de la obra), y una serie de actitudes ante el director y la orquesta. Dicho comportamiento permite al público, reestructurar los significados establecidos en la tradición, dando paso a reacciones fuera de dicho código tradicional, y a su vez conformando una dinámica de comunicación audiencia-intérprete diferente. Sin embargo, la interpretación de la obra musical es fiel a la partitura - la cual se puede observar como un significado dentro del código -, más es enriquecida con los elementos performativos que conforman un nuevo código a través del cuerpo de la cantante, el cual motiva a la audiencia a dar nuevas lecturas a los significados del formato de recital y de una obra específica.

Surge la pregunta ¿es la estructura social-cultural la que ha cambiado? y a su vez, ¿es el intérprete con habilidades multidisciplinarias un reflejo de dichos cambios en la estructura social? Se puede decir, que la mezcla de disciplinas para la interpretación escénica, ya sea teatral, dancística o musical, así como nuevas formas artísticas musicales y escénicas, tales como el happening, el performance, el cine, etc., es un hecho actual tanto práctica como teóricamente.

Por ejemplo, la definición de coreografía que propone Patrice Pavis (1998) en su diccionario del teatro, estipula una eliminación de fronteras dentro del espectáculo contemporáneo, ya que toda interpretación escénica posee una dimensión coreográfica, y esta comprende desde desplazamientos y gestos del intérprete, ritmo del performance, sincronización de la palabra con el gesto, es decir una disposición fundamental del intérprete en escena. Siendo así, se debe prestar atención a la melodía de una dicción, a la coreografía de una escena (p. 96), y agregando en el caso específico de Barbara Hannigan (Mysteries of the Macabre 2015) a la corporalidad de la música.

Se infiere que a los ejecutantes actuales -en su mayoría-, dentro del formato de concierto, es posible observarles desde distintos enfoques, más allá de sus habilidades vocales y su fidelidad a la obra, ya que este elemento conforma sólo una parte de la totalidad de un performance musical.

\section{Conclusión}

Como antes se mencionó, la musicología tradicional mantiene su enfoque de la música bajo la concepción de obra como objeto, situación que relega al intérprete a someterse forzosamente al servicio de la partitura. Con la llegada del giro performativo, el interés se centra en cómo llevar a cabo una interpretación cercana a las ideas, estilo y época del compositor y la obra en particular. Sin embargo, el segundo giro performativo, ofrece una 
visión más amplia de la "música" como fenómeno social-cultural, preguntándose qué es lo que la música hace en un contexto determinado, lo cual incluye, por consiguiente, a una audiencia, al intérprete y a la obra, tres elementos que conforman un performance. Así, desde los EP, el estudio del performance musical nos permite observar puntos de encuentro con otras disciplinas, en este caso específico, la antropología y los estudios teatrales, enriqueciendo la percepción del quehacer musical en la época actual, donde la tradición se puede traspasar desde ciertos aspectos, creando nuevas formas de comunicación por medios performativos desde las prácticas corporales del intérprete.
El acercamiento a dichas prácticas, dentro del performance musical, muestra la mezcla de disciplinas escénicas que el cantante lleva a cabo, haciendo posible una interpretación por medio del cuerpo, dando cuenta que dichas disciplinas son flexibles no sólo ante el repertorio contemporáneo, sino ante el repertorio musical en general. Se añade también la importancia en el entrenamiento en dichas disciplinas, en conjunto con la técnica musical o vocal, infiriendo que las audiencias contemporáneas dentro de la estructura social-cultural de la música académica occidental, tienen una apertura o aceptación mayor al estímulo visual dentro de prácticas musicales cultas.

\section{Bibliografía}

Brenscheidt, D. (2015). La presencia del intérprete. Los estudios del performance y la interpretación musical. En C.L. Hurtado Espinosa et al. (Coords.). Una visión Interdisciplinaria del Arte, ( pp. 7-16). Hermosillo: Universidad de Sonora.

Cook, N. (2013). Beyond the Score. Music as Performance. Oxford: Oxford University Press.

Fischer-Lichte, E. (2006). Volver a leer: la ciencia teatral en la actualidad. El giro performativo de las ciencias de la cultura, (sin paginación). Revista Indagación(20), 15 .

Fischer-Lichte, E. (1999). Semiótica del Teatro. Madrid: Ibérica Grafic, S. A.

H.M. Brown, B. W. (2001). Opera. En S. Sadie (Ed.), The new Grove Dictionary of Music and Musicians (Vol. 18). London: Macmillan.

Komitee, S. (2013). A studet's guide to Performance Studies: An Introduction. (third). S. Brady (Ed.) Routledge. Obtenido de http://www.routledgetextbooks.com/textbooks/_author/schecner-9780415502313/

Ligeti, G. (15 de Enero de 2015). Mysteries of the Macabre. (S. S. Barbara Hannigan, Intérprete) Barbican Hall, Londres, Inglaterra.

Madrid, A. L. (2009). ¿Por qué música y estudios del performance? ¿Por qué ahora?: una introducción al dossier, (sin paginación). Revista Transcultural de Músi$\mathrm{ca}(13), 15$.

Pavis, P. (1998). Diccionario del teatro. Buenos Aires: Paidós, SAICF.

Schechner, R. (2012).Estudios de la representación. Una Introducción. México: FCE

Taylor, D. (2011). Introducción. Performace, teoría y práctica. En D. Taylor y M. Fuentes (Eds.)

Estudios Avanzados del Performance ( pp. 7-30). México, D. F.: Fondo de Cultura Económica.

Turner, V. (1974). Liminal to liminoid, in play, flow, and ritual: an essay in comparative symbology, ( pp. 53-92) Rice Institute Pamphlet, 60(3).

Weber, W. (2001). Recital. En S. Sadie (Ed.), The New Grove Dictionary of Musica and Musicians (Vol.20, pp. 913-915). London: Macmillan. 